\title{
Safety and esthetic outcomes of therapeutic mammoplasty using medial pedicle for early breast cancer
}

\author{
Sameh Roshdy' \\ Osama Hussein' \\ Ashraf Khater' \\ Mohammad Zuhdy' \\ Hend A El-Hadaad ${ }^{2}$ \\ Omar Farouk' \\ Ahmad Senbel' \\ Adel Fathi' \\ Emadeldeen Hamed' \\ Adel Denewer' \\ 'Department of Surgical Oncology, \\ Mansoura Oncology Center, \\ ${ }^{2}$ Department of Clinical Oncology and \\ Nuclear Medicine, Faculty of Medicine, \\ Mansoura University, Mansoura, Egypt
}

Correspondence: Ashraf Khater Department of Surgical Oncology, Mansoura Oncology Center, Faculty of Medicine, Mansoura University, 60 Gomhoria Street, Mansoura 355II, Egypt

Tel +20502358021

Email dr.ashrafkhater@yahoo.com
This article was published in the following Dove Press journal:

Breast Cancer: Targets and Therapy

7 July 2015

Number of times this article has been viewed

Background: Although therapeutic mammoplasty (TM) was introduced for treatment of localized ductal carcinoma in situ and invasive breast carcinoma (stages I and II) in females with large breast size, the suitability of medial pedicle TM for treatment of breast tumors at different locations has not been established. The objective of this study was to assess the safety and esthetic outcome of medial pedicle TM for breast tumors at different locations.

Methods: The study was conducted from February 2012 to July 2014. Consecutive patients with early breast carcinoma with medium- and large-sized breasts, with or without ptosis, who were offered medial pedicle TM were included in the study. Patients who were not candidates for breast-conserving surgery or those with tumors located along the medial pedicle were excluded. All patients received immediate postoperative adjuvant chemoradiotherapy.

Results: Thirty patients with a mean age of 48.5 years received medial pedicle TM in the breast harboring the tumor or, additionally, the other breast $(\mathrm{N}=14)$. The tumors were in the upper $(60.0 \%)$, lower $(26.7 \%)$, and lateral (13.3\%) quadrants. Minor complications occurred in five cases $(5 / 30,16.7 \%)$ in the ipsilateral and in two $(2 / 14,14.3 \%)$ contralateral breasts. No wound dehiscence or areolar necrosis was recorded. A total of $22(73.3 \%)$ patients were scored as excellent cosmesis. After a median follow-up of 20 months, no locoregional recurrence or distant metastases were observed.

Conclusion: TM using a medial pedicle is a safe and appealing technique among women with tumors at different locations.

Keywords: therapeutic mammoplasty, medial pedicle, breast cancer, mastectomy

\section{Introduction}

Esthetic reduction techniques as methods of breast-conserving surgery (BCS) for treatment of localized ductal carcinoma in situ and invasive breast carcinoma (stages I and II) in females with large breast size, known as therapeutic mammoplasty (TM), have been introduced. ${ }^{1-3}$ Such techniques allow tumor resection with generous safety margin and improve the shoulder and neck pain that is commonly associated with huge breast size. ${ }^{4,5}$ Furthermore, delivery of radiotherapy becomes simpler and more reliable with fewer complications after reduction of the breast size.$^{6-9}$ Patients treated with such techniques got adequate local control and equivalent overall survival relative to the traditional mastectomy, in addition to the cosmetic and psychological merits of BCS. ${ }^{10-13}$ There are different techniques of TM. These techniques are fashioned according to the different tumor locations. The most commonly used techniques are the superior-medial and the inferior pedicle mammoplasties. To our knowledge, there is absolute lack of studies examining the suitability of medial pedicle TM for treatment 
of breast tumors at different locations. Vertical reduction mammoplasty using the medial pedicle was described by Elizabeth J Hall-Findlay. ${ }^{14,15}$ This research was designed to evaluate the safety of tumor resection with this technique and its esthetic outcome.

\section{Methods}

\section{Patients}

The study was conducted from February 2012 to July 2014. Consecutive patients with early breast carcinoma who were offered medial pedicle TM were included in the study. Patients of medium- and large-sized breast with or without ptosis were included. Patients who were not candidates for BCS or those with tumors located along the medial pedicle were excluded. All patients were diagnosed through the symptomatic service in our center. All patients were informed about the expected advantages and risks of the procedure, with the possibility of mastectomy, if indicated (in the case of tumor multicentricity or with failure to obtain negative margins after reasonable attempts at reexcision) and written consents were obtained. The study obtained the required approvals from the local ethical committee of Mansoura Oncology Center, Mansoura, Egypt.

\section{Surgical technique}

LeJour pattern was marked over the breast in the usual manner with the patient standing upright (Figure 1) This pattern was modified according to the tumor location. The patient was placed in a supine position with the arm extended to $90^{\circ}$.

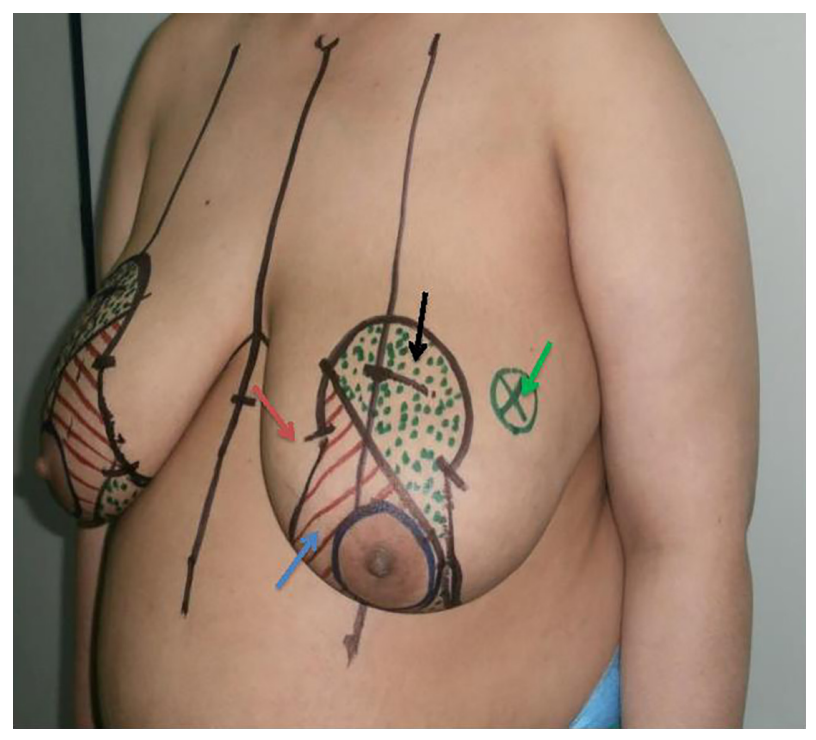

Figure I Planning of the pedicle.

Notes: Black arrow points to the part to be resected; red arrow points to the intact part of the pedicle; blue arrow points to the deepithelialized part of the pedicle; green arrow points to the tumor location marked after ultrasonographic guidance.
The tumor was marked within the breast along with the anticipated resection margin (Figure 1). Intraoperatively, the tumor was resected first using the incisions planned preoperatively to enable optimal oncologic excision. Then, deepithelialization of the pedicle was carried out from around the nipple and areola to the middle of the pedicle without complete pedicle deepithelialization (Figure 2A and B). Immediately after excision, the specimens were sent for frozen sectioning after margin orientation (Figure $2 \mathrm{C}-\mathrm{F}$ ). The median duration of the frozen section procedure was 30 minutes. Margins were considered to be clear if the tumor was at least $1 \mathrm{~mm}$ away from the excision margin. Axillary lymph node dissection was performed for patients with clinically positive axillary lymph nodes through the same incision (Figure 2E) or through a separate axillary incision. Sentinel lymph node biopsy was the standard nodal evaluation in case of node-negative patients. Surgical blade and/or electrocautery was used for preparation of the pedicle and resection of the specimen. Then the tumor bed was marked with titanium clips for planned radiotherapy. A closed suction drain was used for the breast wound. Axillary drainage was also used for patients with axillary surgery. All patients started to use supportive bra at the first postoperative day. Appropriate antibiotic prophylaxis was used. Drains were removed when the drainage was $<50 \mathrm{~mL}$ /day. Contralateral reduction was done simultaneously in eight patients and after radiotherapy in six patients, with a total number of 14 patients (Figure 3).

\section{Adjuvant therapy}

\section{Systemic therapy}

Patients with invasive tumors $>1 \mathrm{~cm}$ or with lymph node involvement received chemotherapy. The most common chemotherapy regimen prescribed was 5-fluorouracil, adriamycin, and cyclophosphamide. Patients with estrogenreceptor-positive tumors received endocrinal therapy with tamoxifen after finishing the radiotherapy.

\section{Radiotherapy}

Patients were treated with three-dimensional conformal radiation therapy, including the whole breast with boost beams to the tumor cavity using a $6 \mathrm{MeV}$ linear accelerator with a dose of 4,500 cGy for the whole breast and $900 \mathrm{cGy}$ as the boost for the tumor cavity. The breast clinical target volume (CTV) included the glandular breast tissue of the ipsilateral breast. The tumor bed CTV was delineated with the guidance of the surgical clips. Breast and boost CTVs were expanded with a margin of $5 \mathrm{~mm}$ to generate the breast and boost planning target volumes. Regional radiation therapy, including 

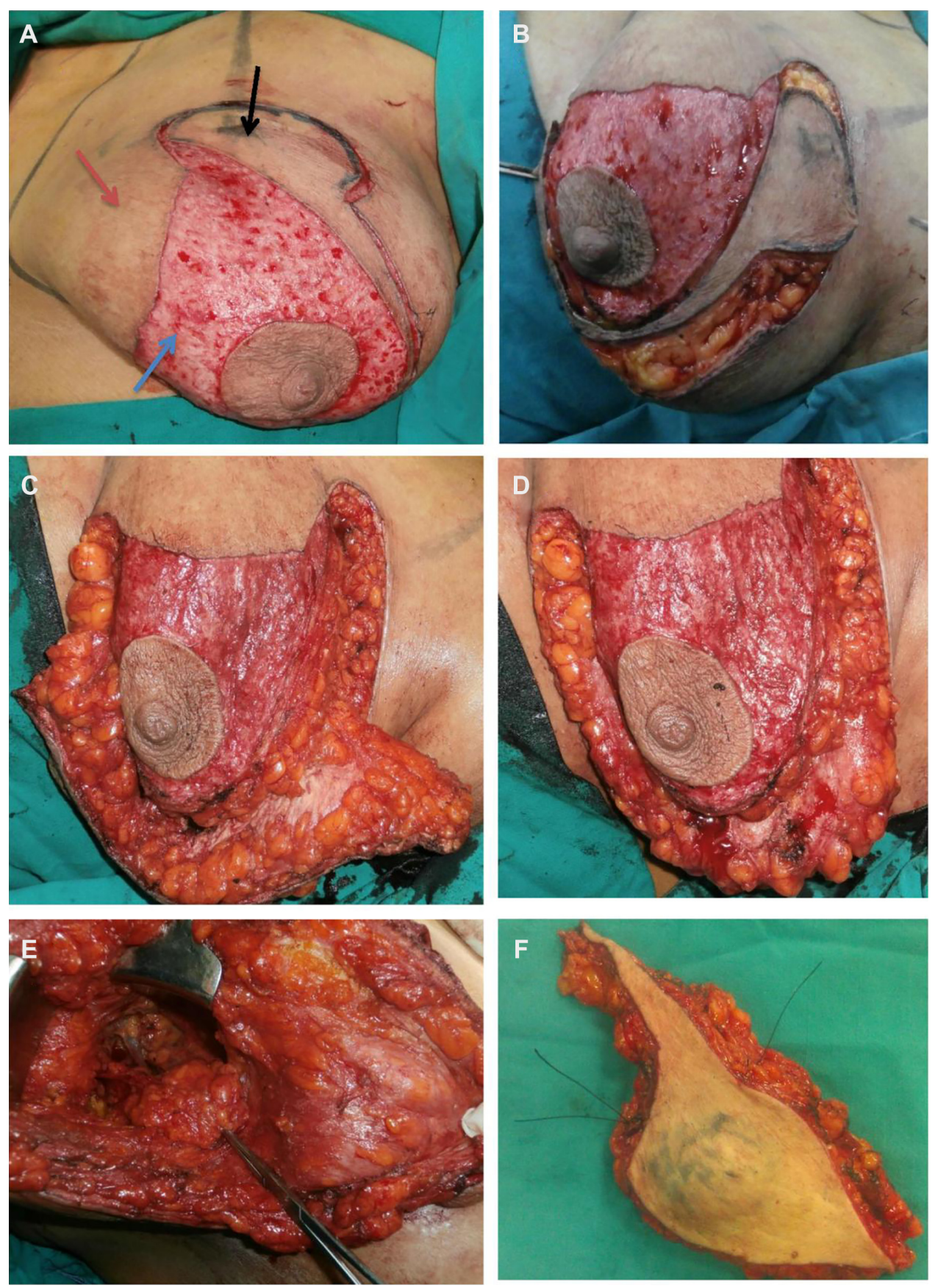

Figure 2 Tumor resection after deepithelialization.

Notes: (A) Deepithelialization of the distal half of the pedicle; black arrow points to the part to be resected; red arrow points to the intact part of the pedicle; blue arrow points to the deepithelialized part of the pedicle; (B and $\mathbf{C}$ ) excision of the tumor-bearing area; $(\mathbf{D})$ appearance after removal of the tumor-bearing area; (E) axillary dissection from the same wound; (F) specimen containing the tumor.

the axillary, supraclavicular, and infraclavicular nodal areas, was carried out in cases with more than three axillary lymph node metastases.

\section{Outcome assessment}

Major postoperative complications were defined as wound dehiscence, areolar necrosis, or fat necrosis, while minor complications were defined as hematoma, infection, or seroma.
Esthetic outcome was assessed at 3 months and 6 months postoperatively. We used a simplified scoring system based on subjective patient satisfaction about her reconstructed breast, which was expressed as excellent (five points), good (four points), satisfactory (three points), poor (two points), and very poor (one point), combined with an objective score based on breast shape, symmetry, and symmetry of the nipple areola complex, which ranged from one to five. We collected 

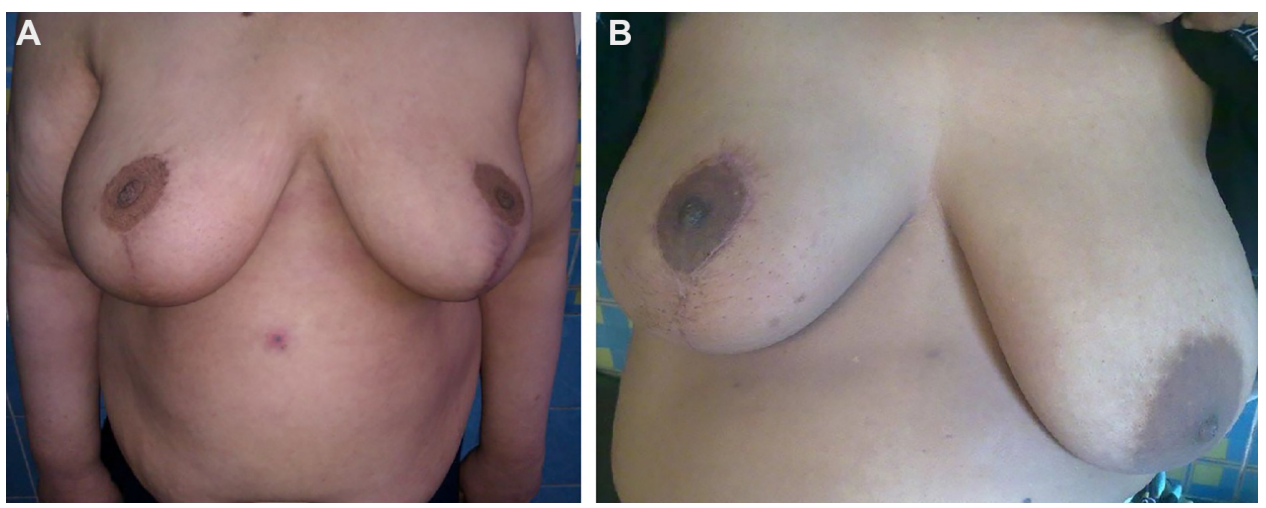

Figure 3 Therapeutic mammoplasty.

Notes: (A) One-month postoperative view after bilateral medial pedicle therapeutic mammoplasty; (B) 3 months after unilateral procedure.

the data gathered from both systems to be expressed as excellent (nine to ten points), good (seven to eight points), satisfactory (five to six points), poor (three to four points), and very poor (one to two points).

\section{Follow-up}

Patient follow-up protocol included complete clinical examination, breast ultrasonography, and diagnostic biopsy from the suspected lesions. Follow-up was done monthly in the first 6 months, then each 4 months after that. Routine metastatic workup and cancer antigen 15-3 (CA15-3) analysis were done as usual. Mammograms were taken for all patients annually, and magnetic resonance imaging was indicated when there were suspected lesions.

\section{Results}

\section{Patient and tumor characteristics}

Thirty women with early breast cancer underwent a medial pedicle TM according to our multidisciplinary breast board panel decision. The mean age of these women was 48.5 years. Tumor characteristics of the patients who underwent medial pedicle TM are shown in Table 1. Tumors were found in the upper outer quadrant of the breast in $18(60.0 \%)$ patients, lower quadrant in eight (26.7\%) patients, and lateral quadrant in four (13.3\%) patients. The majority (93.3\%) of the tumors were confirmed as invasive ductal carcinoma, followed by invasive lobular carcinoma (3.3\%) and medullary carcinoma (3.3\%). The tumor grade was G1 in five (16.7\%) patients, G2 in $22(73.3 \%)$ patients, and G3 in three (10\%) patients. The tumor stage was S1 in six (20\%) patients and S2 in $24(80 \%)$ patients. Tumors were estrogen receptor positive in $23(76.7 \%)$ patients. Lymphovascular invasions were evident in $20(66.7 \%)$ patients. All patients underwent Levels I and II axillary dissection. Conversion to mastectomy was not required in any case. Contralateral reduction was done in eight patients simultaneously and after radiotherapy in six patients. Postoperative tumor characteristics are shown in Table 1. Specimen weight ranged between $220 \mathrm{~g}$ and $840 \mathrm{~g}$. Specimen diameter ranged between $50 \mathrm{~mm}$ and $80 \mathrm{~mm}$ and pathological tumor size ranged between $25 \mathrm{~mm}$ and $50 \mathrm{~mm}$.

\section{Postoperative complications}

Table 2 describes the postoperative complications.

Minor complications occurred in five cases (5/30, 16.7\%) in the tumor-harboring breast and in two $(2 / 14,14.3 \%)$

Table I Tumor characteristics

\begin{tabular}{ll}
\hline Tumor characteristics & $\mathbf{N}(\%)$ \\
\hline Location of the tumor & \\
Upper quadrant & $18(60)$ \\
Lower quadrant & $8(26.7)$ \\
Lateral quadrant & $4(13.3)$ \\
Tumor pathology & \\
Invasive ductal carcinoma & $28(93.3)$ \\
Invasive lobular carcinoma & $1(3.3)$ \\
Medullary carcinoma & $1(3.3)$ \\
Grade & \\
GI & $5(16.7)$ \\
G2 & $22(73.3)$ \\
G3 & $3(10)$ \\
AJCC staging & \\
Stage I & $6(20)$ \\
Stage 2 & $24(80)$ \\
Estrogen receptor status & \\
Positive & $23(76.7)$ \\
Negative & $7(23.3)$ \\
Lymphovascular invasion & \\
Absent & $20(66.7)$ \\
Present & $10(33.3)$ \\
Specimen weight & $220-840 \mathrm{~g}$ \\
Specimen diameter & $50-80 \mathrm{~mm}$ \\
Pathological tumor size & $25-50 \mathrm{~mm}$ \\
Safety margin & $20-40 \mathrm{~mm}$ \\
\hline Ab &
\end{tabular}

Abbreviation: AJCC, American Joint Committee on Cancer. 
Table 2 Postoperative complications

\begin{tabular}{lll}
\hline Complications & $\begin{array}{l}\text { Oncoplastic } \\
\text { breast }(\mathbf{n = 3 0})\end{array}$ & $\begin{array}{l}\text { Contralateral } \\
\text { breast }(\mathbf{n = 1 4})\end{array}$ \\
\hline $\begin{array}{l}\text { Minor complications } \\
\text { Hematoma }\end{array}$ & $2(6.7 \%)$ & $\mathrm{I}(7.1 \%)$ \\
$\quad$ Wound infection & $\mathrm{I}(3.3 \%)$ & $\mathrm{I}(7.1 \%)$ \\
$\quad$ Seroma & $2(6.7 \%)$ & 0 \\
Major complications & & 0 \\
$\quad$ Fat necrosis & 0 & 0 \\
NAC necrosis & 0 & 0 \\
Wound dehiscence & 0 & $2(14.3 \%)$ \\
Total & $5(16.7 \%)$ &
\end{tabular}

Abbreviation: NAC, nipple/areolar complex.

contralateral breasts. Wound dehiscence or areolar necrosis was never recorded. No major complications were recorded. Wound dehiscence or areolar necrosis was never recorded.

\section{Esthetic outcome}

In our study, $22(73.3 \%)$ patients were scored as excellent, four $(13.3 \%)$ patients were scored as good, and four $(13.3 \%)$ patients were scored as satisfactory (Figure 3).

\section{Oncologic outcome}

At a median follow-up of 2 years, no locoregional recurrences were detected. No distant metastases were recorded. Median death-free survival was 14.6 months ( $95 \%$ confidence interval $=13.2-15.8)$.

\section{Discussion}

We are reporting for the first time the safety and esthetic outcomes among a cohort of Egyptian patients. Resection to a negative margin is an essential requirement to decrease recurrence. ${ }^{16}$ In fact, oncoplastic surgery of the breast allows inclusion of larger tumors in breast conservation and decreases the rate of positive margins and need for reexcision. ${ }^{17,18}$

Approximately $60 \%$ of the tumors in the current study were found in the upper outer quadrant of the breast. Similarly, the outer sector of the breast was shown to harbor most of the breast carcinomas. ${ }^{19}$ One-half of breast cancers affect the upper outer quadrant alone. ${ }^{20,21}$ Thus, an effective versatile oncoplastic technique should be applicable in cases with outer half location. The ideal technique should include a medially based vascular nipple/areolar pedicle. Routine reduction mammoplasty techniques had utilized either superiorly based or inferiorly based pedicles for the nipple/areolar complex. In the cancer setting, many tumors encroach on the anatomical site of the pedicle and lead to inevitable conflict between the radical resection and safe reduction techniques. We believe that an ideal reduction technique should include a medially based vascular pedicle that would be away from the majority of breast tumors. The detection of relatively fewer cases in this study is due to the wide variety of oncoplastic techniques used in our institute; among them is this technique that is set to become more popular. We are reporting low level of minor complication rates, with no major complications. Our complications rate is probably better than that with other techniques that use the superomedial pedicle or the inferior pedicle..$^{22}$ In a study by Denewer et al, ${ }^{23}$ which used a superomedial pedicle, the rate of wound dehiscence was $8 \%$ (four out of 50 cases) and the rate of partial necrosis of the areola was $4 \%$ (two out of 50 cases). A study by Gulcelik et $\mathrm{a}^{24}$ using the inferior pedicle reported an incidence of $3 \%$ minor wound dehiscence, $1 \%$ major wound dehiscence, $1 \%$ areolar necrosis, and 5\% seroma. A higher complications rate was reported by Denewer et $\mathrm{al}^{25}$ on using an inferior pedicle. ${ }^{25}$ They reported an incidence of $17.6 \%$ of wound dehiscence, $14.7 \%$ of seroma, and 3\% of partial areolar necrosis. In our study, neither areolar necrosis nor wound dehiscence was encountered, which reflects the vascular reliability of the medial pedicle. This is not surprising because it is the shortest pedicle of all TMs (Figure 2). Additionally, in our series, the deepithelialization did not involve the whole pedicle but just the distal half (Figure 2). The relatively shorter oncologic outcome reported is actually going to be addressed in a separate work to assess the oncologic safety of this technique over a longer follow-up period of at least 5 years. Finally, we can summarize the advantages of this technique over the other TMs; it is a very simple technique with an easy learning curve, it is suitable for most of the commonly located breast tumors, we can do axillary dissection through the same wound with no need for a separate incision, and finally it has the shortest pedicle that is deepithelialized only to its middle; thus, it has the least incidence of wound dehiscence and areolar necrosis. The median tumor size in the current study was $4 \mathrm{~cm}$ (range: $2.5-5 \mathrm{~cm}$ ). In this group with relatively larger tumors, we achieved a low rate of positive resection margin $(0.03 \%)$. Reexcision was not required and local recurrence was not encountered after a median follow-up period of 20 months (range: 18-24 months). We believe that this favorable outcome is in part due to the anatomical arrangement of the vascular pedicle that lies away from the tumor bed, which minimized the conflict between oncological and reconstructive intraoperative decisions and allowed an effective oncoplastic procedure. In our study, the esthetic outcome was found to be higher than in other studies $(73.3 \%$ patients were scored as excellent versus $64 \%$ by Denewer et $\left.\mathrm{al}^{23}\right)$. 


\section{Conclusion}

In conclusion, among a cohort of Egyptian women with relatively large-sized tumors, TM using the medial pedicle was a feasible, reliable, safe, and appealing technique for various and commonly encountered early breast tumors.

\section{Acknowledgment}

The authors are thankful to Professor Dr Aiman Elsaed for his assistance and guidance throughout this work.

\section{Disclosure}

The authors report no conflicts of interest in this work.

\section{References}

1. Clough KB, Kroll SS, Audretsch W. An approach to the repair of partial mastectomy defects. Plast Reconstr Surg. 1999;1999(104):409.

2. Fisher B, Anderson S, Bryant J, et al. Twenty-year follow-up of a randomized trial comparing total mastectomy, lumpectomy, and lumpectomy plus irradiation for the treatment of invasive breast cancer. N Engl J Med. 2002;347(16):1233-1241.

3. Clarke M, Collins R, Darby S, et al; Early Breast Cancer Trialists' Collaborative Group (EBCTCG). Early Breast Cancer Trialists' Collaborative Group (EBCTCG). "Effects of radiotherapy and of differences in the extent of surgery for early breast cancer on local recurrence and 15-year survival: an overview of the randomised trials". Lancet. 2005;366:2087-2106.

4. Curran D, van Dongen JP, Aaronson NK, et al. Quality of life of earlystage breast cancer patients treated with radical mastectomy or breastconserving procedures: results of EORTC Trial 10801. The European Organization for Research and Treatment of Cancer (EORTC), Breast Cancer Co-operative Group (BCCG). Eur J Cancer. 1998;34:307.

5. Al-Ghazal SK, Fallowfield L, Blamey RW. Comparison of psychological aspects and patient satisfaction following breast conserving surgery, simple mastectomy and breast reconstruction. Eur J Cancer. 2000;36:1938.

6. Clough KB, Lewis JS, Couturaud B, Fitoussi A, Nos C, Falcou MC. Oncoplastic techniques allow extensive resections for breast-conserving therapy of breast carcinomas. Ann Surg. 2003;2003(237):26-34.

7. Veronesi U, Cascinelli N, Mariani L, et al. Twenty-year follow-up of a randomized study comparing breast-conserving surgery with radical mastectomy for early breast cancer. $N$ Engl J Med. 2002;347:1227-1232.

8. Losken A, Styblo TM, Carlson GW, Jones GE, Amerson BJ. Management algorithm and outcome evaluation of partial mastectomy defects treated using reduction or mastopexy techniques. Ann Plast Surg. 2007;59: 235-242.
9. Asgeirsson KS, Rasheed T, McCulley SJ, Macmillan RD. Oncological and cosmetic outcomes of oncoplastic breast conserving surgery. Eur J Surg Oncol. 2005;2005(31):817-823.

10. McCulley SJ, Macmillan RD. Planning and use of therapeutic mammoplastye Nottingham approach. Br J Plast Surg. 2005;58: 889-901.

11. Rainsbury RM. Surgery insight: "oncoplastic breast-conserving reconstruction indications, benefits, choices and outcomes". Nat Clin Pract Oncol. 2007;4:657-664.

12. Iwuchukwu OC, Harvey JR, Dordea M, Critchley AC, Drew PJ. The role of oncoplastic therapeutic mammoplasty in breast cancer surgery a review. Surg Oncol. 2012;21:133-141.

13. Bartelink H, Horiot JC, Poortmans PM, et al. Impact of a higher radiation dose on local control and survival in breast-conserving therapy of early breast cancer: 10-year results of the randomized boost versus no boost EORTC 22881-10882 trial. J Clin Oncol. 2007;25:3259-3265.

14. Hall-Findlay EJ.A simplified vertical reduction mammaplasty: shortening the learning curve. Plast Reconstr Surg. 1999;104(3):748-759.

15. Hall-Findlay EJ. Vertical breast reduction. Semin Plast Surg. 2004; 18(3):211-224.

16. Crago AM, Azu M, Tierney S, Morrow M. Randomized clinical trials in breast cancer. Surg Oncol Clin NAm. 2010;19(1):33-58.

17. Hussein O, El-Khodary T. "Diamond" mammoplasty as a part of conservative management of breast cancer: description of a new technique. Int J Surg Case Rep. 2012;3(6):203-206.

18. Chakravorty A, Shrestha AK, Sanmugalingam N, et al. How safe is oncoplastic breast conservation? Comparative analysis with standard breast conserving surgery. Eur J Surg Oncol. 2012;38(5):395-398.

19. Losken A, Dugal CS, Styblo TM, Carlson GW. A meta-analysis comparing breast conservation therapy alone to the oncoplastic technique. Ann Plast Surg. 2014;72(2):145-149.

20. Lee AH. Why is carcinoma of the breast more frequent in the upper outer quadrant? A case series based on needle core biopsy diagnoses. Breast. 2005;14(2):151-152.

21. Darbre PD. Recorded quadrant incidence of female breast cancer in Great Britain suggests a disproportionate increase in the upper outer quadrant of the breast. Anticancer Res. 2005;25(3c):2543-2550.

22. McCulley SJ, Macmillan RD. Therapeutic mammaplastye analysis of 50 consecutive cases. Br J Plast Surg. 2005;58:902-907.

23. Denewer A, Shahatto F, Elnahas W, et al. Therapeutic reduction mammoplasty in large-breasted women with cancer using superior and superomedial pedicles. Breast Cancer (Dove Med Press). 2012;4: 167-172.

24. Gulcelik MA, Dogan L, Camlibel M, et al. Early complications of a reduction mammoplasty technique in the treatment of macromastia with or without breast cancer. Clin Breast Cancer. 2011;11(6):395-399.

25. Denewer A, Elnahas W, Hussein O, Khater A, El-sadda W, Abouelkher K. Evaluation of inferior pedicle therapeutic mammoplasty as a primary procedure for upper quadrants early breast cancer. Adv Breast Cancer Res. 2013;2:86-90.
Breast Cancer: Targets and Therapy

\section{Publish your work in this journal}

Breast Cancer: Targets and Therapy is an international, peerreviewed open access journal focusing on breast cancer research, identification of therapeutic targets and the optimal use of preventative and integrated treatment interventions to achieve improved outcomes, enhanced survival and quality of life for the cancer patient.

\section{Dovepress}

View the full aims and scopes of this journal here. The manuscript management system is completely online and includes a very quick and fair peer-review system, which is all easy to use. Visit http:// www.dovepress.com/testimonials.php to read real quotes from published authors. 